\title{
TEORIA ORGANIZACIONAL: A ÓTICA DA CULTURA E DO DESENVOLVMENTO LOCAL
}

\author{
Por Marcelo Dantas \\ Professor e pesquisador do NEPOL e coordenador do PACTU na UFBA. \\ Doutor em Sociologia pela Universidade de Paris VII. \\ E-mail: mdantas@pucnet.com.br
}

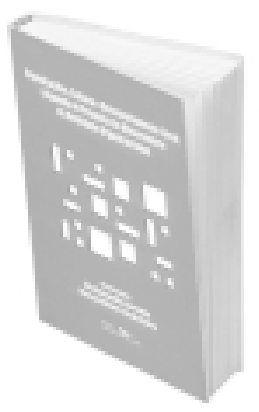

\section{ORGANIZAÇÕES, CULTURA E DESENVOLVIMENTO LOCAL: A AGENDA DE PESQUISA DO OBSERVATÓRIO DA REALIDADE ORGANIZACIONAL}

De Cristina Amélia Carvalho e Marcelo Milano Falcão Vieira (Organizadores)

Recife: Editora Universitária - UFPE, 2003. 1a edição, 366 p.

Antes de falar do conteúdo ambicioso do livro, é importante registrar a importância da sua publicação como expressão da maturidade de um núcleo de pesquisa na área de estudos organizacionais: o Observatório da Realidade Organizacional, coordenado pelos organizadores da obra, Cristina Amélia Carvalho e Marcelo Milano Fal cão Vieira. 0 livro demonstra justamente o caminho percorrido pelo grupo: sua reflexão sobre as teorias contemporâneas e a investigação da realidade local. 0 viés da cultura foi o escolhido para, a partir dos estudos empíricos da realidade da região metropolitana de Recife, buscar a sua consonância com as questões teóricas e metodológicas que nos são contemporâneas na área de estudos organizacionais.

0 livro é dividido em duas partes: a primeira - "Reflexões teóricas" marca a opção do grupo em pautar suas análises institucionalistas ou neoinstitucionalistas; a segunda "Investigações empíricas" - volta-se para a realidade, buscando nela luzes para a reflexão teórica. N essa divisão em duas partes, residem paradoxalmente os estímulos e as angústias que movem as pesquisas em área como a nossa, do universo das Ciências Sociais Aplicadas: por um lado, a busca de consistência teórica para aprimorar o ol har que vai tentar, por outro lado, explicar o mundo real que pulsa à nossa volta. E o livro é um vigoroso exemplo dessa divisão tão presente na alma do pesquisador.

$\mathrm{N}$ a primei ra parte, que tem o subtítulo "A bordagem institucional, poder e derivações", a opção pela abordagem institucional é muito bem traduzida pelos organizadores no texto intitulado "Contribuições da perspectiva institucional para a análise das organizações: possibilidades teóricas, empíricas e de aplicação". Os autores fazem uma análise do estado da arte da abordagem institu- 
cionalista de modo a apresentar o seu surgimento e desenvolvimento por meio de vários campos das ciências sociais, seus principais autores e os atuais defensores dessa corrente, os chamados neoinstitucionalistas. No segundo artigo - "Instituições e poder: explorando a possi bilidade de transferências conceituais" - , um espaço mais aprofundado para a crítica a eventuais fragilidades da abordagem institucional é desenvolvido por Marcelo Milano Falcão Vieira e Maria Cecy Mizoczky no qual os autores apontam as fragilidades dos institucionalistas na concepção de poder. A esses se agregam os artigos de J osé Ricardo Costa de M endonça, que traz uma retrospectiva do tema e sua utilização por pesquisadores brasileiros; de Rosimeri Carvalho e Eloísa Helena Livramento Dellagnelo, que investiga os caminhos propostos por novas abordagens sobre o mundo das organizações, buscando caracterizar essas novas formas organizacionais e, finalmente, analisando a questão do controle e a renovação das suas práticas; e de Sueli Goulart e M arcelo Milano Falcão Vieira, que analisa a evolução do conceito de desenvolvimento local, suas contradições, os limites de algumas abordagens, e também busca compreender o papel das universidades no desenvolvi- mento local sob a luz dos impasses teóricos atuais.

A segunda parte do livro é subdividida em outras duas: na primeira, intitulada "O mundo da cultura e suas organizações", seis artigos destacam a abordagem da cultura; na segunda, "Desenvolvimento e organizações locais", mais cinco artigos priorizam as relações da cultura com o desenvolvimento. Esses onze artigos são, sem dúvida, a contribuição mais valiosa do Observatório da Realidade O rganizacional: os membros do grupo de pesquisa partem para a investigação da realidade pernambucana, analisando teatros, maracatus e times de futebol, buscando, a partir de pesquisas empíricas, elaborar a sua contribuição para os estudos organizacionais.

Em seu conjunto, os artigos mostram um grande esforço de análise das organizações e manifestações culturais de Pernambuco, buscando nelas a expressão de questões teóricas que pautam o universo das organizações contemporâneas. Capítulos como "Da origem pagã às micaretas: a mercantilização do carnaval", de Gustavo Madeiro e Cristina Amélia Carvalho; "M aracatu pernambucano: resistência e adaptação na era da cultura mundial izada", de Rodrigo Gameiro, MichelleFerreira de M enezes e Cristina Amélia Carvalho; "Parceri- as entre ONGs e empresas: uma relação de poder camuflada", de Távia Correia Monte; e "Sobre a falácia da relação direta entre turismo e desenvolvimento local", de Luciana Araújo de Holanda e M arcelo Milano Falcão Vieira, mostram o fôlego do grupo em aliar a criati vidade da investigação empírica e o aguçado espírito crítico nas análises que produzem.

O livro resulta numa valiosa contribuição de um grupo de pesquisa brasileiro para a evolução da nossa produção na área de Organizações, a partir da ótica da cultura e do desenvolvimento local. A consistência evidente dessa produção, que alia teorias contemporâneas e abordagens empíricas, aponta para os novos desafios que se colocam para o Observatório da Realidade Organizacional: ampliar os estudos e as abordagens objetivando contribuir, juntamente com outros pesquisadores brasileiros, para a produção de teorias organizacionais elaboradas a partir da análise da nossa própria realidade. A nossa singularidade como país de rica diversidade cultural nos faz crer que sejamos capazes de construir elaborações teóricas novas, que venham a se tornar uma contribuição, além das fronteiras nacionais, para os estudos organizacionais. 0 desafio está lançado. 